\title{
An Analysis on Legal Translation in a Functionalist Approach
}

\author{
Jun Song * \\ Foreign Language School, Southwest University for Nationalities, Chengdu 610041, China. \\ songjundhu@aliyun.com
}

\begin{abstract}
This paper carries out a comparative study of traditional translation approach and functionalist translation approach, and then proposes a theoretical framework in which the functionalist translation approach is applied to legal translation. Functionalist theory is adapted for analysis of legal translation phenomena, which may offer an alternative to traditional translation.
\end{abstract}

Keywords: Legal translation; functionalism; Skopostheorie; adequacy; loyalty principle.

\section{Introduction}

Up to now, there appears to be no consensus reached on the acceptable translation techniques to legal translation. The application of a general translation theory to the legal texts was once taken for granted by translation theorists. However, it is argued that special methods and techniques are required in translating the legal texts. Given this backdrop, this paper seeks to verify the feasibility of Skopostheorie as the guidelines for legal translation.

\section{Traditional vs. Functionalist Translation Approach}

\subsection{Equivalence vs. Adequacy.}

The term "equivalence" in translation was first introduced by E. V. Rieu in 1953. And "translation equivalence" has, ever since, become the focus of study in linguistic-oriented western translation theories. In the light of communication, Eugene A. Nida introduced the dynamic or functional equivalence method, which aims at a response of the target text receptors that is similar to that of the source text receptors, rather than at a literal translation of the original text. That is, the relation of target language receptors to the target language text should be roughly equivalent to the relation of the original receptors to the original text. As Nida said, "The readers of a translated text should be able to understand and appreciate it in essentially the same manner as the original readers did." (Nida, 1999, p.118) People's attitudes toward Nida's theory are varied. Some gave a critical reaction to Nida's theory, holding that equivalence in translation is merely an ideal to strive for, but difficult to attain, and very often is realized only to a certain degree (Šarčević, 1997, p.70).

The traditional linguistic approach set "equivalence" as the criterion for legal translation. But this criterion is much more idealistic than realistic. And the requirement for definite equivalence extremely suppresses the legal translator's subjectivity and is thus in contrast to the new trend in legal translation practice as co-drafting is beginning to incorporate legal translators into the legislating process. Admitting that it is impossible to achieve an absolute equivalence in legal translation, theorists came to the conclusion that one should discard the term entirely or develop a new dynamic concept of equivalence.

Within the framework of Skopostheorie, 'adequacy' refers to the qualities of a target text with regard to the aim of the translational action: the translation should be 'adequate to' the Skopos. It has to be clarified that Reiss's concept of 'adequacy' does not negate equivalence entirely. The Skopos of the translation determines the form of equivalence required for an adequate translation (Nord, 2001, p.36). For example, a literally and structurally faithful translation of legal documents is deemed as equivalent and at the same time adequate, when the target text is expected to be a faithful reproduction of the words and structures of the source legal text.

However, an adaptation of obscure statutes can hardly be regarded as an equivalent translation but can still be deemed as adequate if such an adaptation is required by the translation Skopos, for popularizing those statutes among elementary students. 


\subsection{Bottom-up Approach vs. Top-down Approach.}

In traditional translation, the procedure usually starts from the basic elements - — word and phrase and moves gradually to the sentence level, and then to the paragraph, and the whole text. This text is eventually polished stylistically until it seems acceptable (from the translator's personal point of view) for the communicative situation it is intended for. This is a bottom-up approach. Such an approach works from the linguistic text-surface structures (Stage 1) to conventions (Stage 2) and finally to pragmatics (Stage 3). As such, it is highly contingent on the translators' own stylistic references and the limitations of their linguistic and translational competence (Nord, 2001, p.67). In the bottom-up approach, translating can be seen as a code-switching operation where lexical or syntactic equivalences play the most important part. Then some translators may lose sight of how the text, as a whole, functions in its communicative situation. Consequently, translators fail to follow the given direction of translation. Moreover, a decision made at a lower level often has to be revised when reaching the next level. Sometimes, the translation process is even blocked because of apparent untranslatability.

Functionalist theory proposes to adopt a top-down approach, which means that a functional translation process should start from the pragmatic level by deciding on the intended function of the translation. By comparing the Skopos with the source-text functions before starting to translate, translators should be able to locate the problems that may arise in the translating process. They should thus be able to devise a holistic strategy for their solution (Nord, 2001, p.14). According to functionalist theory, the people or agents involved in the translation are: the initiator, which is the person, group or institution that starts off the translation process and determines its course by defining the purpose for which the target text is needed; the commissioner, which is the person who asks the translator to produce a target text for a particular purpose and addressee; the ST producer; the TT producer; the TT user, which is the one who finally puts it to use; and the TT receiver, who is the addressee of the translation. In legal translation, the government acts as the initiator as well as the commissioner of the translation process. It is the government who decides the translation Skopos. Depending on his responsibility and competence, the translator decides what translation strategy to use, or what translation type to choose. Then the functionalist translation procedure can be summarized hierarchically as follows:

1. the translator interacts with the initiator to identify the Skopos of the translational action;

2. the translator goes through text typological analysis (which can further break down into target analysis and source analysis);

3. the translator decides certain strategies.

Since the functionalism deals with translation problems in a top-down way, the translator has more authority to manipulate the whole translation process than those who adopt a bottom-up translation approach. It is by the translator's interaction with the initiator that the Skopos of the translation is identified. And it is his source- and- target-text analysis and function analysis that finally lead him to decide translation strategies. As such, the legal translator succeeded in converting his/her passive role in the communication process into an active one.

\subsection{Invisibility vs. Visibility.}

For a long time, traditional translation theories have tended to consider the translation as a faithful reproduction of the source text. Moreover, both Chinese and Western Translation Studies are source-text oriented. Translators are denied the right to make their own decisions during the translating process. The inferiority of the translator in traditional theories is also revealed by the idea of the translator's invisibility, which means the translator will make the ideal translation as a piece of completely transparent glass through which one can see the original, and make the translated text read as if it had been, from the outset, written in that original language. As a result, translators should try their best to reduce their subjective involvement and "reproduce in the receptor language the closest natural equivalent of the source-language message, first in terms of meaning and second in terms of style" (Nida, 1982, p.55). 
Legal translation demands a precision that may not be required in other types of translations. Therefore, legal translators' first consideration has long been fidelity to the source text. The fear that the original intent will be tainted by the translator's subjectivity is undoubtedly one of the main reasons why the legal translators could in the past play only a highly restricted role. For this reason, it has taken much longer for legal translators to gain even limited authority to make decisions concerning linguistic questions (Šarčević, 1997, p.91).

It is evident in Hönig's view that visibility of the translator is a key concept in functional approaches. According to Hönig (1998, p.12-13), in functionalism the translator inevitably has to be visible, since functional approaches do not establish rules but support decision-making strategies and the translator has to make critical decisions as to how define the translation Skopos and which strategies can best meet the target recipient's requirements; s/he should be visible, making his/her decisions transparent to his/her client and accepting the responsibility of his/her choices. A visible translator has to accept the consequences of his /her translational decisions.

As people's knowledge of translation activities deepens, the translator has moved from behind the curtain to the forefront and has become a visible subject from an invisible ghostly presence.

\section{Applicability of the Functionalist Translation Theory to Legal Translation}

\subsection{Skopos Rule-the Top-Ranking Rule.}

According to Vermeer's Skopostheorie, there are three major rules in the Skopostheorie, namely, the Skopos rule, the coherence rule and the fidelity rule. Among these rules, the Skopos rule is the top-ranking rule, which means that Skopos determines a translational action in the translation process. The Skopos rule intends to help translators break the fetters of free and faithful translation, dynamic and formal equivalence, good interpreters and slavish translators, etc, which means that the Skopos of a particular translation task may require a 'free' or a 'faithful' translation, or anything between these two extremes, depending on the purpose for which the translation is needed (Nord, 2001, p.29).Then, who decides the translation Skopos? The translation brief offers us the answer to the question. The translation brief specifies what kind of translation is needed and tends to provide the specific translation requirement according to the initiator. We can take the translation of laws and regulations organized by the Bureau of Legislative Affairs of the State Council of the PRC for example. According to data collected via the Internet, the guiding principles (translation Skopos) for the translation of Chinese laws and regulations are as follows: firstly, to meet the needs of people at home and abroad who require a comprehensive understanding of China's laws and regulations; secondly, to provide an effective reference for foreigners who will engage or are engaging themselves in economic activities, lawsuits and arbitration issues in China; thirdly, to inject new impetus into the progress of China's economy, thereby contributing to the revival of China in the world stage.

As is shown above, the translation brief does not tell the translator how to go about their translating job, what translation strategy to use, or what translation type to choose. These decisions depend entirely on the translator's responsibility and competence (Nord,2001, p.30).

\subsection{Coherence Rule \& Fidelity Rule-the Basic Requirements.}

The coherence rule and the fidelity rule proposed by Vermeer help the translators to achieve a specific translation Skopos by offering two basic translation criteria: (1) coherence rule (intratextual coherence) specifies that a translation should be acceptable in a sense that it is coherent with the receiver's situation (Reiss and Vermeer, 1984, p.113, cit. Nord, 2001, p.32). This means the receiver should be able to understand it; and it should make sense in the communicative situation and culture in which it is received. A communication can only be regarded as successful if the receivers interpret it as being sufficiently coherent with their situation; (2) fidelity rule (intertextual coherence) specifies that there exists some kind of relationship between the source text and the target text, while the form it takes depends both on the translator's interpretation of the source text and on the translation Skopos (Nord, 2001, p.32). One possible kind of intertextual coherence could be a maximally faithful imitation of the source text (Nord, 2001, p.32). 
Legal text falls within the category of 'frozen style' (Qin, 1997, p.141). Therefore, legal translation should mirror the precision, authoritativeness and solemnness of the legal text. Only when the goal of intratextual and intertextual coherence is attained, can the precise and concise effects of the target-text be better achieved.

\subsection{Loyalty Principle-the Moral Code.}

Although most legal translators would try their best to achieve a certain communicative effect, the text receiver may still have difficulty in comprehending the target text. Why? Well, it has something to do with the moral responsibility the translator has toward the translation if he/she is already equipped with a required skill and experience. Under such circumstances, Nord proposes her loyalty principle, which commits the translator bilaterally to the source and target sides. It refers to the responsibility the translator has toward the source text producer, the target receiver and other agents involved in a translational interaction. Loyalty demands the translator should be responsible for the target readers, but this does not mean that the translator is always obliged to do exactly what the readers expect. Yet at the same time, the translator should also have a sense of moral responsibility not to deceive his readers (cf. Nord, 1991, p.94f, cit. Nord, 2001, p.125).

It can be seen that the loyalty principle endows the translators with a strong sense of responsibility. It not only helps to enhance the translators' status in the translational action, but also encourages the translators to take into consideration the interest of the source text producer and the target receiver and to be held responsible for his /her product.

\section{Summary}

To sump up, the Skopos rule is the top-ranking rule for legal translation; the coherence rule and fidelity rule are the basic requirements to achieve a specific translation Skopos; and the loyalty principle is the moral code that legal translators should abide by, it reinforces translator's sense of responsibility.By suggesting a worthy theoretical framework for legal translation, this thesis makes an effort to associate functionalist theory with legal translation practice. Functionalist theory is adapted for analysis of legal translation phenomena, which may offer an alternative to traditional translation.

\section{Acknowledgement}

This work is supported by the Fundamental Research Funds for the Central Universities, Southwest University for Nationalities (No. 2015SZYQN54).

\section{References}

[1]. Nida, Eugene A. Language, Culture, and Translating. Foreign Language Education Press,1999, p. 118-119

[2]. Nord, Christiane. Translating as a Purposeful Activity. Shanghai Foreign Language Education Press, 2001, p. 30-32, p. 125-126

[3]. Šarčević Susan. New Approach to Legal Translation. Kluwer Law International, 1997, p. 91-92

[4]. Hong, H.G. Positions, Power and Practice: Functionalist Approaches and Translation Quality Assessment, 1997, Current Issues in Language and Society. Vol.4(1997) Issue 1, p.12-13

[5]. Reiss, Katharina. Translation Criticism: The Potentials and Limitations. Shanghai Foreign Language Education Press, 2004, p. 56-57

[6]. Venuti, Lawrence. The Translator's Invisibility: A History of Translation. Shanghai Foreign Language Education Press, 2004, p.32-33 